\title{
MIRADAS DESDE LA OTREDAD. LA CONSTRUCCIÓN DE LA IMAGEN DE BOLIVIA EN LA OBRA FOTOGRÁFICA DE LUIGI DOMÉNICO GISMONDI
}

\author{
GAZES FROM OTHERNESS. CONSTRUCTION OF THE IMAGE OF BOLIVIA \\ IN THE PHOTOGRAPHIC WORK OF LUIGI DOMENICO GISMONDI
}

\author{
Pedro Querejazu Leyton*
}

\begin{abstract}
Este trabajo presenta la obra del fotógrafo Luigi Doménico Gismondi activo en Bolivia, el norte de Chile y el sur del Perú entre 1897 y 1946. Describe y analiza la manera de mirar, de encontrar y construir historias con la imagen fotográfica.

Palabras claves: Imagen, fotografía, fotografía histórica, representación social, otredad, indígena originario, indianismo, indigenismo, identidad, Bolivia, Chile, Perú.
\end{abstract}

This paper presents the work of photographer Luigi Gismondi of Doménico active in Bolivia, northern Chile and southern Peru between 1897 and 1946. It describes and analyzes how to look, to find and build stories with the photographic image.

Key words: Image, photography, historic photography, social representation, otherness, indian, indianism, indigenism, identity, Bolivia, Chile, Peru.

\section{Introducción}

A lo largo del tiempo tanto la pintura como la fotografía han sido elementos esenciales en la construcción y conformación de identidades locales, grupales, regionales y nacionales. Contribuyeron a esa construcción al registrar las peculiaridades y diferencias que marcan las identidades y establecen los límites y las fronteras. Luigi Doménico Gismondi es uno de los varios fotógrafos que con su obra, especialmente con su manera de mirar, contribuyó notablemente a la construcción de la imagen de Bolivia.

Los antecedentes de la construcción de la imagen de América y de los americanos datan de la época de la llegada de Cristóbal Colón al Caribe, en su ruta al oriente por occidente. Este navegante se encontró con un continente hasta entonces desconocido por los habitantes del viejo mundo. América se convirtió desde entonces en el lugar donde cualquier utopía o imaginación era posible, en territorio sin límites, un nuevo mundo. Desde ese tiempo se produjo un ansia por conocer ese territorio nunca imaginado, real y fantástico. A partir de entonces se fue construyendo un imaginario simbólico acerca de América, sus habitantes (felices salvajes, desnudos y tocados de plumas), y sus maravillas como los pájaros parlantes, el cerro Rico de Plata, Eldorado; en resumen: el Paraíso Terrenal. Los relatos escritos requirieron también de las representaciones visuales. Eso coincidió con el desarrollo en Europa de la imprenta y el de la técnica del grabado en metal.

Theodore De Bry fue uno de los más tempranos ilustradores de América, sin siquiera haber salido de su país, en Flandes. Viajeros y cronistas incorporaron ilustraciones propias o ajenas en sus relatos, como fray Diego de Ocaña. Dentro de este panorama está la afamada Nueva Corónica y Buen Gobierno, 1616, de Felipe Guamán Poma de Ayala. Durante el último tercio del siglo XVIII, como parte de la instalación del pensamiento moderno y del enciclopedismo ilustrado se desarrollaron las series de pinturas de castas y se realizaron nuevas crónicas y relaciones descriptivas, como la Crónica de Moxos del padre Eder, sj; el informe del obispo Martínez Compañón en Trujillo del Perú, o el Informe de Lázaro de Rivera, gobernador de Moxos, de 1797, que estuvo acompañado por un álbum de acuarelas y dibujos hechos por Manuel Oquendo, describiendo a los grupos humanos, especies animales y vegetales, paisajes y caminos.

\footnotetext{
* Academia Boliviana de la Historia, La Paz, Bolivia. Correo electrónico: pedroquerejazu@ gmail.com
} 
A principios del siglo XIX se hicieron populares registros en acuarela y papel como los de Pancho Fierro, el pintor costumbrista limeño. Obra ilustrada, fundamental en la historiografía sobre Bolivia, es la de Alcides D'Orbigny, que estuvo en el país entre 1830 y 1834 , y que publicó entre 1835 y 1847 , en nueve tomos con once volúmenes ilustrados, con el título: Viaje por América meridional.

Dentro de la tónica del cientifismo ilustrado y racionalista del pensamiento moderno, el abogado, fotógrafo y político Melchor María Mercado hizo a lo largo de varios años el: Álbum de Paisajes, Tipos Humanos y Costumbres de Bolivia (1841-1869) (Mendoza 1991).

Durante el siglo XIX, tras el ocaso del imperio español y el surgimiento del imperio británico y el nuevo colonialismo europeo y norteamericano, se desarrolló el capitalismo y se redefinieron nuevas relaciones comerciales e industriales entre los países. En ese momento se desarrolló la fotografía que inmediatamente se usó como medio de registro, al que inmediatamente se le adjudicó un altísimo grado de fidelidad en la representación.

En la segunda mitad del siglo XIX aparecieron los libros ilustrados con grabados basados en fotografías. Para el último cuarto del siglo se desarrollaron las técnicas fotomecánicas que posibilitaron imprimir las fotografías directamente sobre el papel en libros y periódicos (Querejazu 2016, Imágenes).

La fotografía, basada en su verosimilitud y su posibilidad de reproducirse en múltiples ejemplares de cada sujeto contribuyó tanto o más que los antiguos grabados y álbumes de acuarelas a redefinir una imagen de América, de los americanos, y de Bolivia y de los bolivianos, con una mirada doble: la de los extranjeros fascinados por lo exótico y original, y la de autodefinición desde lo local en pos del reconocimiento del otro externo.

\section{Gismondi y el contexto Boliviano y Sur Andino}

Luigi Doménico Gismondi, 1872, emigró de Módena, Italia, al Perú, con parte de su familia (Buck 1999). Como muchos europeos, vino a América porque en su país de origen no tenía oportunidades de trabajo, incluso carecían de alimentos suficientes para sobrevivir. Él, con sus hermanos mayores Jacinto y Esteban, desembarcaron en Mollendo, Perú, hacia 1892, y establecieron allí una casa comercial. Sus dos hermanos eran fotógrafos y estuvieron activos en Cusco, Arequipa y el sur del Perú ya desde 1895 (Garay 2011).

Luigi Doménico Gismondi empezó a peregrinar como fotógrafo al parecer desde esos mismos años trabajando en el sur del Perú, norte de Chile y el occidente de Bolivia. Estuvo activo en Bolivia desde 1901, y en 1904 fijó su residencia en La Paz junto con su esposa. En 1907 instaló en esta ciudad un estudio formal: Foto Estudio Gismondi, que fue el centro de su actividad profesional, hasta su muerte en 1946.

En esas cinco primeras décadas del siglo XX sucedieron muchos eventos y cambios a nivel mundial, continental, regional y nacional, así como en la tecnología fotográfica y en el cómo representar y autorrepresentarse por medio de la fotografía.

En Bolivia, tras la guerra civil de Los Cruceros, en 1899, el Partido Liberal triunfante trasladó la sede del gobierno de Sucre a La Paz, y gobernó en Bolivia durante las siguientes dos décadas. La ciudad de La Paz era entonces relativamente pequeña, con alrededor de 40.000 habitantes, disfrutó las mejoras urbanas y edilicias gracias a los recursos económicos de la indemnización que Chile pagó a Bolivia por los territorios usurpados en la costa del Pacífico, así como por Brasil por los territorios del Acre, al norte. Sus elites sociales y políticas estuvieron imbuidas del positivismo e industrialismo que caracterizó a esa época en todo el continente. Si bien La Paz era una ciudad chica para los estándares de la época, era sin duda una de las más atractivas, interesantes y pujantes de la región surandina, zona que, dicho sea de paso, estaba mucho más comunicada entre sí de lo que hoy suponemos.

Durante esas primeras décadas del siglo XX se publicaron varios libros emblemáticos en el país: Wara-Wara, 1904, Pueblo Enfermo, 1909, y Raza de Bronce, 1919, de Alcides Arguedas (fundamentos ideológicos del emergente indigenismo); El Ayllu. Estudios Sociológicos Sobre América, 1914, de Bautista Saavedra; el ensayo La Creación de la Pedagogía Nacional, 1910 y numerosos poemarios entre 1898 y 1927, como la Prometeida o las Oceánides, 1917, de Franz Tamayo; Terres Embrasées, 1931, de Adolfo Costa du Rels.

En 1925 se conmemoró el primer centenario de Bolivia como República independiente. El gobierno organizó la Exposición del Centenario y se produjo, entre muchas actividades, una exposición industrial y un concurso internacional de arte y de fotografía. Ese año José María Velasco Maidana realizó la 
película La Profecía del Lago. En 1926 se fundó en La Paz la Academia Nacional de Bellas Artes.

En 1928 apareció el cine sonoro. En Bolivia, Velasco Maidana presentó la película Wara Wara, con guión de Antonio Díaz Villamil. En 1932 se produciría la película Hacia la gloria.

Entre 1932 y 1935 se desarrolló la Guerra del Chaco, entre Bolivia y Paraguay, que desangró en hombres y recursos a ambos países. El drama de la guerra generó en Bolivia cambios sociales y culturales de largo impacto.

Después de la contienda, Augusto Céspedes publicó sus obras Sangre de mestizos, 1936, de relatos de la Guerra del Chaco, y más tarde la novela Metal del diablo, 1946; por su parte, Oscar Cerruto publicó Aluvión de fuego, 1935, novela, relacionada con la guerra. También se creó la Normal Rural de Warisata, en el altiplano paceño, para formar indígenas originarios como docentes rurales que impartieran la educación en lengua aymara.

Durante las primeras décadas del siglo XX, también se produjeron cambios en la fotografía debidos a los constantes desarrollos tecnológicos que tuvieron consecuencias en la manera de mirar, registrar y reproducir la realidad. El desarrollo por parte de George Eastman, de los soportes de celuloide durante las últimas dos décadas del siglo XIX, permitió la elaboración de rollos de película y alivianar y achicar las cámaras fotográficas que fueron de gran uso, en el formato 120, especialmente por los amateurs y viajeros, hasta el logro en 1931 de una película capaz de registrar toda la gama del espectro lumínico, la Verichrome Pan (Querejazu 2016, Gerstmann).

"Al comienzo el fotógrafo era el encargado de realizar todos los pasos necesarios para tener una imagen, desde la elaboración del material sensible, la exposición, revelado, y copiado de este hasta su montaje final. Con el proceso de industrialización que la fotografía fue alcanzando desde fines del siglo XIX, los primeros años del nuevo siglo permitían adquirir fácilmente diversos tipos de productos, como lentes cada vez más finos y luminosos, cámaras fotográficas con tiempos de exposición más cortos, obturadores más rápidos, material sensible elaborado industrialmente (notablemente placas secas) y papeles de impresión de gelatina y colodión para revelado químico que permitían realizar grandes ampliaciones" (Martínez 2006).

\section{Gismondi y el registro de los territorios y sus habitantes}

La obra de Luigi Doménico Gismondi es importante en dos escenarios distintos pero complementarios e inseparables: el registro del territorio y el de los habitantes. Viajó prácticamente por todo el territorio boliviano, aunque la mayor parte de su trabajo estuvo centrada en La Paz y su departamento, con una labor transfronteriza en el norte de Chile (el antiguo litoral boliviano) y el sur y centro del Perú; además del sur de Bolivia, la República Argentina y Paraguay.

Gismondi realizó un amplio registro fotográfico del país. Sus fotografías de las montañas, el altiplano, los valles mesotérmicos y los tropicales de los Yungas en torno a La Paz, así como de la ciudad y de sus calles y monumentos, son tradicionales en su concepción y realización. Mérito de Gismondi es que su obra constituye una de las primeras secuencias de registro sistemático del paisaje de La Paz y su región, de sus pormenores urbanos, así como del patrimonio monumental construido en el país, rural y urbano.

Gismondi realizó fotografías con la luz natural del sol en horas generalmente comprendidas entre la media mañana y la media tarde, aunque también realizó dramáticos contraluces con luz de madrugada o atardecer y también nocturnas. Visto el conjunto de su obra se hace evidente que evitó los acentuados contrastes de la iluminación natural, tan característicos en las tierras altas. Son raras las fotografías con cielos encapotados por las nubes. Sin embargo, debieron impresionarle mucho las nubes sobre La Paz que aparecen en algunas de sus fotografías. Al parecer incomodaron a Gismondi los limpios cielos de la época seca coincidente con el invierno, pues en buena parte de los casos intervino los negativos incorporando nubes en las imágenes.

Para el registro de los edificios y monumentos Gismondi buscó preferentemente composiciones diagonales, evitando las vistas frontales y simétricas, aun cuando en muchas ocasiones le era posible realizarlas. En algunos casos hizo las fotos del único ángulo posible dadas las condiciones impuestas por el urbanismo, así como las posibilidades que entonces brindaban las ópticas, como el caso de la fachada de la iglesia de Santo Domingo de La Paz, el patio del claustro en demolición del antiguo Convento de la Concepción o la portada del antiguo Seminario. 
Gismondi fue el primero que realizó en Bolivia un registro fotográfico sistemático de los monumentos coloniales y republicanos del país, de manera comparable al trabajo realizado por Guillermo Khalo en México entre 1901 y 1940, que fuera contratado por el gobierno de México para hacer fotografías de arquitectura; por Abraham Guillén activo entre 1925 y 1955 en Lima y Cuzco, y, Hans Mann, que por encargo de la Academia Nacional de Bellas Artes de Argentina, realizó fotografías de monumentos coloniales y obras de arte en ese país, en las tierras altas de Bolivia y en el sur del Perú.

El registro del paisaje hecho por Gismondi es formidable por la mirada sorprendida y maravillada de este fotógrafo y porque es fiel a la manera de mirar de su tiempo, en que el país se descubría y se reconocía a sí mismo gracias a la obra de los fotógrafos. Es también valioso por la mirada fresca de lo que probablemente para sus contemporáneos nativos del país fuese cotidiano. Es formidable por el interés en hacer y repetir secuencias de los mismos lugares en diferentes momentos, pero sobre todo por la calidad de su paisaje, su búsqueda de lo original y extraordinario, tanto por los temas elegidos como por incorporar el drama en el registro y la representación. Esto último es apreciable cuando se tiene la oportunidad de comparar las placas originales o contactos de las mismas y los positivos realizados por el propio fotógrafo, más intensos y contrastados, casi quemados.

Gismondi fue también uno de los primeros fotógrafos industriales del país pues hizo registros fotográficos de los principales asientos mineros así como los ferrocarriles y otros medios de transporte modernos. Debió recibir numerosos encargos oficiales y privados para realizar fotografías de ingenios y asientos mineros, así como de unidades industriales. Entre los campamentos e instalaciones dedicadas a la minería destaca varios de la Patiño Mines $\mathrm{C}^{\mathrm{o}}$, como Oploca, cerca de Tupiza en Sud Chichas, Departamento de Potosí, antigua hacienda agrícola que tenía ganado vacuno y producción de leche para los centros mineros de la empresa, o Huanchaca, en Pulacayo, Departamento de Potosí, de perteneció a la empresa de Aniceto Arce. La mayor parte de estos encargos han debido realizarse antes y en torno al Primer Centenario de la República, 1925, pues numerosísimas fotografías realizadas por este autor figuran publicadas en el libro memoria de ese evento: Bolivia en el Primer Centenario de su Independencia (Alarcón 1925). Parte de los encargos recibidos con ese fin debió ser el registro de ciudades y poblaciones rurales del país como las de los países vecinos, atravesando las fronteras; ejemplo de esto son las tomas realizadas en Arica, tanto del Morro, como del puerto, la Catedral y la ciudad; como las de Arequipa, Tacna y Mollendo en Perú. Las fotos que Gismondi marcó como Bella Vista - Todos Santos, demuestran que estuvo en el Departamento Beni junto con la unidad militar del Regimiento Padilla, que hacía prospecciones y habría trocha para el futuro camino carretero al Beni. Otro tanto sucede con las fotografías en las riberas bajas del río Pilcomayo en la parte que este separa el antiguo Chaco boliviano de Argentina, antes de la guerra. Gismondi cruzó las fronteras, tanto hacia Argentina como hacia Paraguay, como acreditan sus fotos de los indios Leguas, asentados en ese último país, y otros de la región como los Choroti que consideraban al Pilcomayo como el centro de su vida y su territorio (Querejazu 2016, Chaco).

Es notorio como Gismondi procuró siempre incorporar personas dentro de sus paisajes, como componentes de los mismos. Esto es particularmente notorio cuando se compara su obra con la de varios de sus contemporáneos, como la de Roberto Gerstmann, por ejemplo, que procuró evitar la presencia de personas en sus paisajes y vistas urbanas (Querejazu 2016, Gerstmann).

Como la mayoría de los fotógrafos profesionales de esa época, Gismondi estableció un estudio fotográfico permanente en La Paz en 1907, el Foto Estudio Gismondi, aunque ya radicaba en la ciudad desde 1904 (Estudio Gismondi 2007).

La parte principal del trabajo en el estudio fue el retrato formal de individuos y grupos, y también, ocasionalmente, el retrato a domicilio o in situ como motivo de eventos importantes para los clientes. En el registro de los acontecimientos sociales relevantes están tanto las devociones como los afectos y los sentimientos. Es notable la fotografía que hiciera de la imagen de la Virgen de Copacabana en su camarín, en el Santuario del lago Titicaca. El fotógrafo repitió la propuesta de la pintura barroca en trampantojo, del periodo virreinal, en que los pintores retrataban de manera muy realista a las imágenes de altar que gozaban de gran devoción, entre ellas, la Copacabana. En este caso él la enmascaró para solo dejar visible la imagen de la Virgen María con el Niño Jesús. La devoción mariana, tan arraigada en el pueblo, fue 
también representada por Gismondi en la escenificación y montaje en estudio que muestra a una anciana indígena de cuclillas, en actitud de orar ante una pequeña imagen de la Virgen Inmaculada. La pequeña escultura italiana que representa al Niño Jesús apoyado en su cruz es testimonio de la renovada devoción por el Niño Jesús, el Divino Niño, El Niño Jesús de Praga, a principios del siglo XX en América Latina.

La muerte es un tema registrado repetidamente por Gismondi. Los sepelios, velatorios, y entierros han constituido siempre acontecimientos sociales en los que las familias y las sociedades presentan y expresan su dolor y son acompañadas por actos de cierre. Su trabajo de registro de los cuerpos de antiguos habitantes prehispánicos desenterrados, desprovistos de los ropajes de los fardos funerarios, es notable. Si bien las fotografías pudieron haberse hecho como registro documental y probablemente por encargo, llama la atención el respetuoso tratamiento de Gismondi con los difuntos retratados; incluyendo las tomas de velatorios infantiles de sus propios hijos y los de otras familias. Un primer ejemplo, de hacia 1907, muestra a una niña de alrededor de dos años, con los ojos entreabiertos, vestida y calzada de blanco; el segundo es el registro de la muerte de Juan Bautista, el 25 de agosto de 1921, de pocos meses; el tercero muestra una habitación llena de ramos de flores en medio de la cual está un catafalco con el cuerpo yerto de un niño de cerca de seis años. Una muerte que impactó al país fue la del aviador teniente coronel Rafael Pabón que el 12 de agosto de 1934 cayó en combate aéreo con un avión paraguayo, en la zona de Fortín Florida, durante la guerra del Chaco. Pabón fue considerado el "As" boliviano, con tres victorias y derribos en numerosas acciones con aeronaves enemigas. La obra de Gismondi registra la capilla ardiente y la celebración de la misa de cuerpo presente en homenaje al héroe.

Entre los eventos sociales, fue extraordinario por sus características y su rara ocurrencia en la vida boliviana, el fusilamiento en la Plaza Sucre de la ciudad de La Paz, el año 1922, del reo condenado por el asesinado del expresidente José Manuel Pando. Gismondi se ubicó en un balcón de una casa que hace esquina con el lado noroccidental de la plaza. El fusilamiento del reo se ejecutó contra el muro que entonces cerraba el atrio de la iglesia de San Pedro. En la toma se aprecia al fondo el torreón sur del edificio del Panóptico Nacional, más conocido como Cárcel de San Pedro. Una poblada de curiosos se reunió para presenciar el extraordinario evento que la imagen muestra instantes después de la ejecución.

Parece razonable presumir que el estudio fotográfico de Luigi Doménico Gismondi se sostenía con el trabajo de retrato en el estudio o en los domicilios de los retratados. La gama de los personajes retratados es muy amplia, desde aquellos del ámbito público, del gobierno e Iglesia, hasta individuos y familias acomodadas, así como las de clase media en todo su espectro, incluyendo pudientes mujeres mestizas, las cholas.

Como retratista, fotografió a numerosos personajes del mundo oficial paceño y boliviano. En cuanto a la fotografía oficial, Luigi Doménico Gismondi realizó retratos de todos los Presidentes de la República desde José Manuel Pando (1899-1904) hasta Gualberto Villarroel (1943-1946). De entre ellos, sorprendente por su espartana austeridad es la del presidente Siles Reyes, con la medalla y la banda presidencial, acompañado tan solo por un Ministro y un General. Entre los altos funcionarios destaca el retrato del general Fermín Prudencio, Ministro de Guerra entre 1917 y 1920. En el Archivo del Estudio Gismondi se encuentran también retratos de personajes de la diplomacia, como el nuncio apostólico Rodolfo Carolli, o miembros de la jerarquía eclesiástica de la Iglesia católica, como los Arzobispos de La Paz y numerosos canónigos catedralicios. Dentro del mismo tipo descrito se encuentran los innumerables retratos de sociedad de gente de alcurnia y la de clase media, entre ellas los profesionales independientes, mujeres solas o con sus hijos.

Destacan los retratos de las cholas, representadas por Gismondi con gran garbo y prestancia. Este tema fue sociológicamente complicado, porque pertenecían a un estrato social intermedio de personas racialmente mestizas y económicamente independientes dedicadas especialmente al comercio. Los cholos eran despreciados tanto por las elites blancas como por los indígenas originarios, encima de los cuales estaban en la pirámide social. Parte del problema lo constituyó el encholamiento, que fue parte de los mecanismos de ascenso de y descenso social, según se mire (Romero 2015). Las cholas fueron tema privilegiado de los fotógrafos; la producción más grande conocida, aparte de la de Gismondi, (Figura 1) es la de Julio Cordero Castillo, pero existen muchas otras realizadas por Max $\mathrm{T}$. 


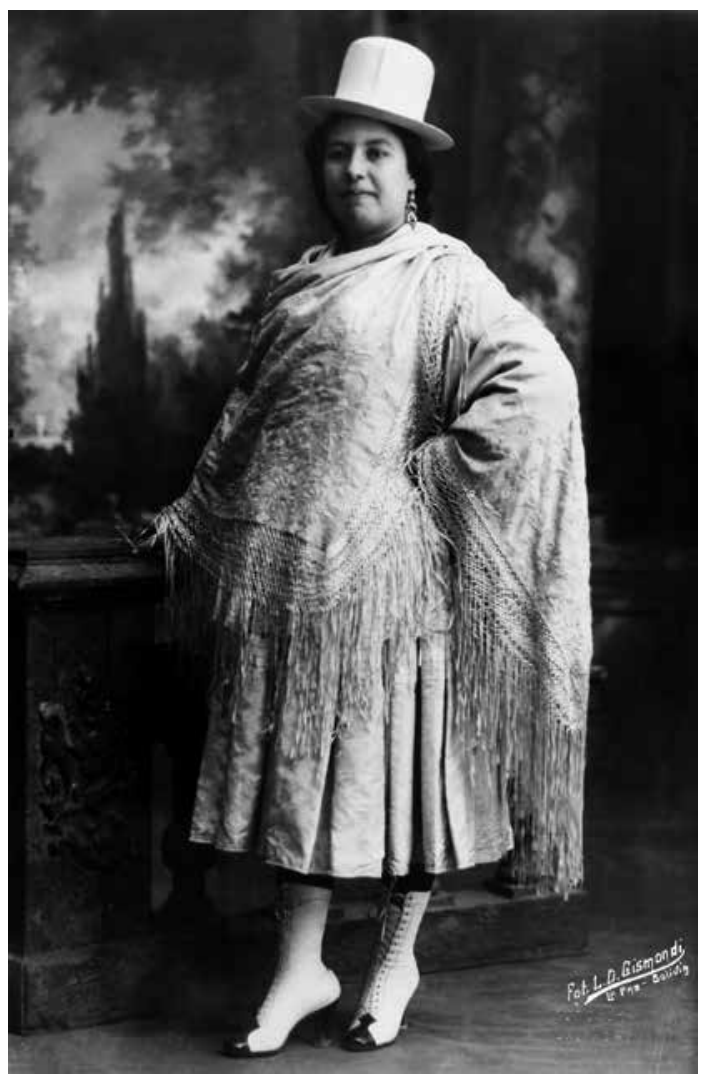

Figura 1. L.D. Gismondi. Chola paceña, gran dama. Hacia 1920. Archivo Estudio Gismondi. La Paz. Bolivia.

Vargas, J.N. Piérola, los hermanos Kavlin y otros, realizadas tanto en La Paz como en Oruro, Potosí, Cochabamba, Sucre y Tarija. Estos retratos son testimonio de la alta autoestima de estas mujeres de la clase social emergente en el país, y de cómo ellas los usaron como instrumento de legitimación social y nivelación con las elites urbanas; así como, y por otra parte, del intenso uso comercial que los fotógrafos hicieron del tema como personajes típicos de La Paz y otras ciudades (Querejazu 2015, M. T. Vargas).

Llama la atención la buena cantidad de retratos de indios y mendigos fotografiados por Gismondi. Lo más probable es que hayan sido realizados por el fotógrafo, como una iniciativa personal para la producción ulterior de postales de personajes característicos de La Paz.

En su trabajo profesional, en el retrato de estudio, cumplió a la perfección los estándares de la época. Aunque Luigi Doménico ejerció la fotografía en momentos en que esa había desarrollado una madurez tecnológica respecto del siglo XIX tanto en las cámaras, ópticas y equipos, como en los materiales sensibles y de laboratorio, en su trabajo se aprecian las restricciones inherentes a ese momento general, como los tipos de iluminación, la necesidad de la quietud y la consecuente ausencia de escenas en movimiento en los interiores. Más allá de los aspectos técnicos, su trabajo respondió al tipo de retrato desarrollado y adoptado como típico de la época: composiciones centrales, simétricas; actitudes hieráticas y estudiadas en los personajes, con poses convencionales, heredadas del retrato pictórico y de la primera etapa de la fotografía.

Una faceta que resulta importante dentro de la actividad retratística de Gismondi es la del autorretrato. Además de los realizados en estudio, es notoria la presencia del propio Gismondi dentro de sus fotografías tempranas, realizadas a lo largo de la primera década del siglo XX, Durante la década y media entre 1911 y 1925, Luigi Doménico Gismondi incorporó con frecuencia a alguno o varios de sus hijos dentro de las fotografías. Según las épocas se puede identificar a sus hijos Julio César, Luis Adolfo o Luis Antonio y ocasionalmente también a sus hijas mayores, como en el patio de la Casona Diez de Medina, hoy Museo Nacional de Arte.

Donde Luigi Doménico Gismondi se manifiesta como un fotógrafo formidable es en los retratos individuales o de grupo de personajes que han sido especialmente escogidos por él mismo, como las tomas realizadas en estudio, tal: la Lechera, El Yatiri o Colliri, las numerosas versiones de las cholas, el Indio Aimara-Bolivia, Indio Quechua-Perú, o la Princesa Incaica. Llaman la atención los retratos de personajes con atuendo festivo, ya sea que se traten de los interesados bailarines o los modelos que usó Gismondi como el Moreno, Danzante Indígena o el Músico de Diablada. Las cholas son frecuentemente representadas con uno o los dos brazos en jarro para resaltar tanto su garbo y elegancia como la magnífica calidad de sus vestiduras, mantas, blusas, polleras, sombreros, calzados, posando delante de bucólicos telones de fondo. Estas fotografías solían tener gran éxito pues eran compradas por viajeros y visitantes así como las reproducciones impresas como tarjetas postales (Querejazu 2015). Independientemente de lo típicos o comunes que pudieran ser estos retratos, llama la atención el tratamiento que de sus modelos hizo Gismondi, resaltando la belleza de sus rasgos y la personalidad y dignidad de los retratados, particularmente en los personajes 
despreciados por la sociedad, maltratados por la vida, y víctimas de la injusticia social, como los indígenas originarios y en las ciudades los mendigos y pongos. La representación de estos personajes es estética y conceptualmente contemporánea a la pintura como el Mendigo, 1915, de Ángel Dávalos y El Yatiri, 1918, de Arturo Borda.

Lo más interesante de la producción retratística de Gismondi son los primeros planos de rostros de indios en los que el fotógrafo lee y presenta la personalidad de cada personaje. Dentro de estos llama la atención el hombre retratado de frente, mirando a la cámara, así como los rostros de tres cuartos de dos versiones de Retrato de indígena. Estas fotografías, realizadas hacia 1909, fueron un notable anticipo al movimiento indigenista de la tercera década del siglo, relacionado con la publicación de los ya mencionados libros Pueblo Enfermo y Raza de Bronce de Alcides Arguedas y El Ayllu de Bautista Saavedra. Por otra parte son paralelos a los estudios antropológicos y sociológicos que se realizaron en varias partes de América, tanto con cráneos y restos humanos procedentes de las excavaciones arqueológicas en Tiahuanacu y otros lugares, como con los indígenas originarios mediante tomas con cámaras fotográficas especiales para respaldar los estudios antropométricos.

Lo descrito para los retratos y composiciones de estudio, donde el autor tenía total control sobre el entorno, es también válido para los retratos al aire libre y con iluminación natural diurna. Ejemplo de su buen trabajo son los retratos de los jefes Charotes en el Pilcomayo, y el grupo familiar en Bella Vista.

En la obra de Gismondi se aprecia que el fotógrafo, con ojos de extranjero maravillado, buscó con sus imágenes decir o mostrar la verdad, individuos, grupos, lugares y realidades patentes. No obstante, hombre de su tiempo, también construyó discursos visuales para contar historias. Presento algunos ejemplos que demuestran lo dicho. El primero se refiere a la chola mencionada antes. En segundo lugar, la fotografía de los jefes charotes; (Figura 2) que es un retrato in situ, en un escenario natural y con iluminación del medio ambiente. El fotógrafo registró a los protagonistas a modo de un diálogo con ellos, diferente de la manera de representar especímenes etnológicos que caracterizó a la fotografía de fines del siglo XIX. El tercero, la fotografía de las piedras de Queri-Cala, en Tiahuanaco, (Figura 3) que presenta una vista de magníficos bloques de piedra labrados, tumbados en la bastedad del altiplano.

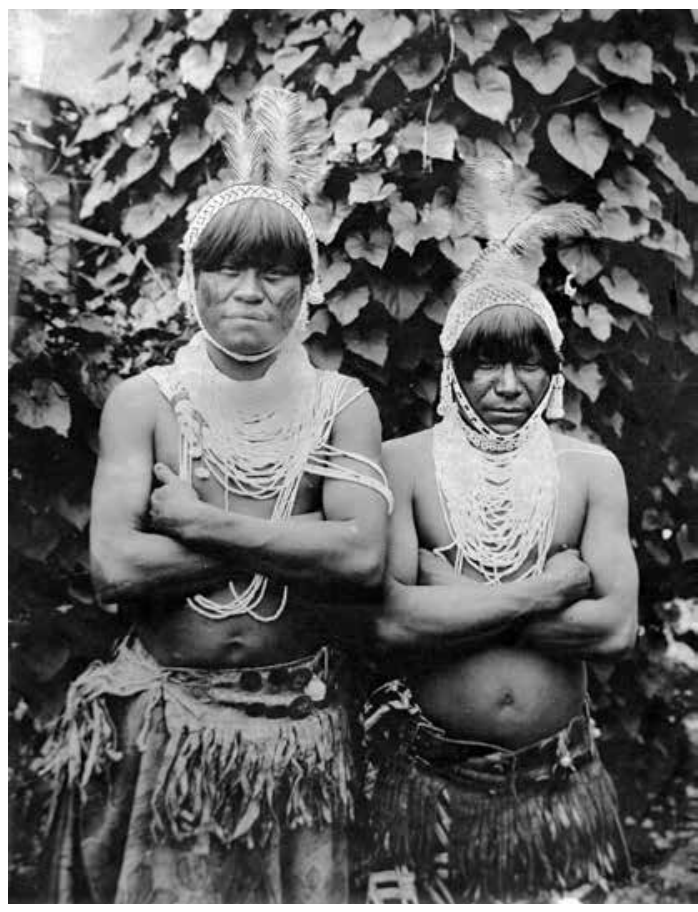

Figura 2. L.D. Gismondi. "Jefes Charotes" (habitantes del bajo río Pilcomayo; Argentina y Bolivia). Hacia 1902-1909. Archivo Estudio Gismondi. La Paz. Bolivia.

La imagen es sugestiva por las interrogantes que transmite sobre esos indígenas del pasado que construyeron esa formidable civilización panandina, y al mismo tiempo incorpora en la toma a un muchacho indígena originario. Pudiera pensarse que está puesto como escala humana para resaltar la magnificencia y magnitud de las piedras labradas, pero sutilmente este personaje trae la imagen a la realidad presente, no es un escenario teatral ni cinematográfico. Adicionalmente el fotógrafo establece una relación de filiación genética, racial y cultural entre los indígenas originarios antiguos y los de hoy.

Otros ejemplos de esa actitud y mentalidad, y paradójicamente el mayor anacronismo, se encuentran en algunos de sus retratos de estudio en que se hace evidente que el fotógrafo buscó satisfacer una demanda, un mercado de imágenes, y mostró a los personajes como verdaderos, pero para ello construyó discursos específicos. El anacronismo está en que presentó a los personajes retratados en estudio, con un fondo pintado cuya apariencia dista mucho de ser contextualmente verídica respecto de las personas retratadas. Los personajes posan en 


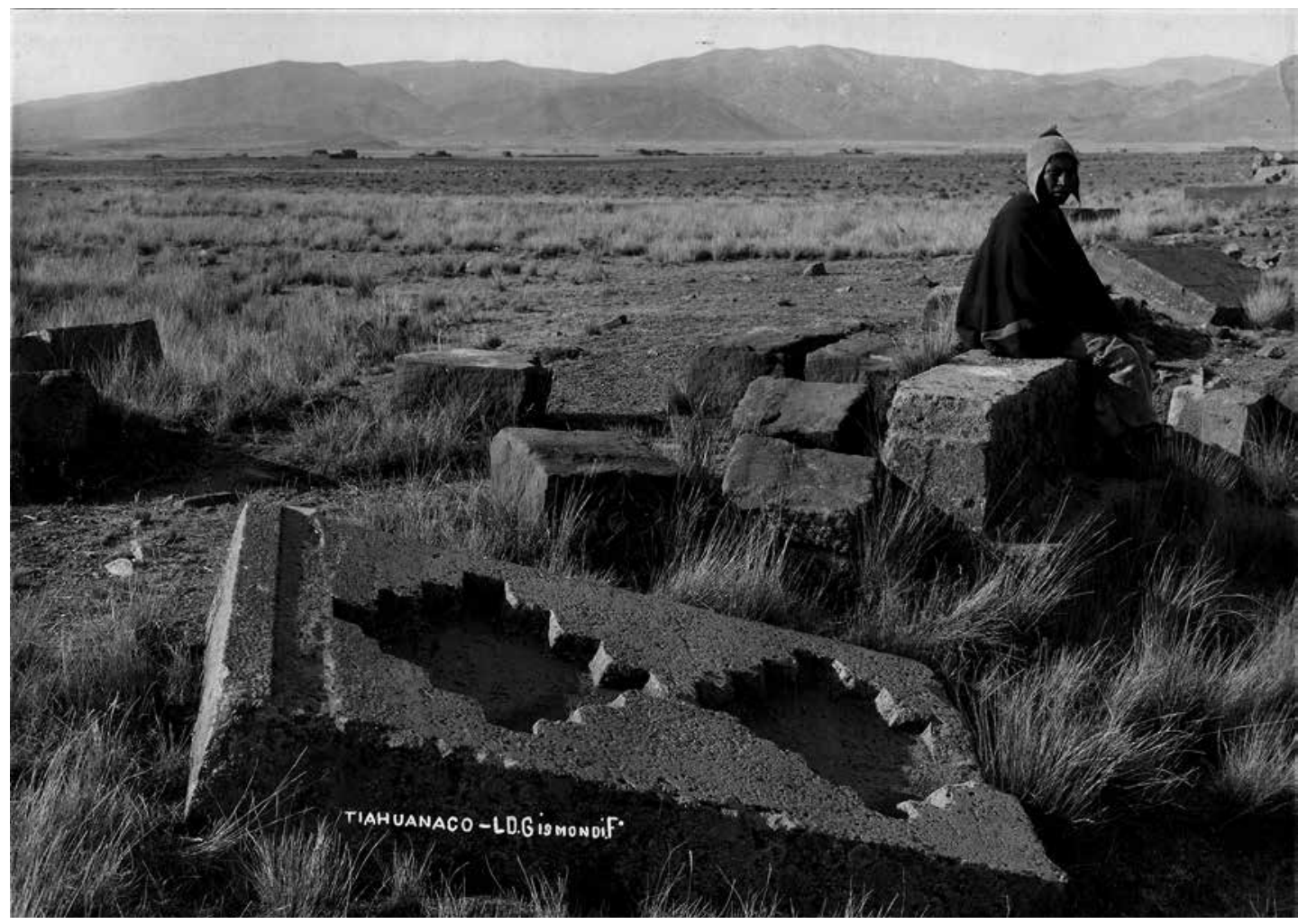

Figura 3. L.D. Gismondi. Tiahuanaco (Piedras de Queri-Cala). Hacia 1907. Positivo original. Gelatina-plata y papel, 20 x $25 \mathrm{~cm}$. Colección Diran Sirinian. Buenos Aires. Argentina.

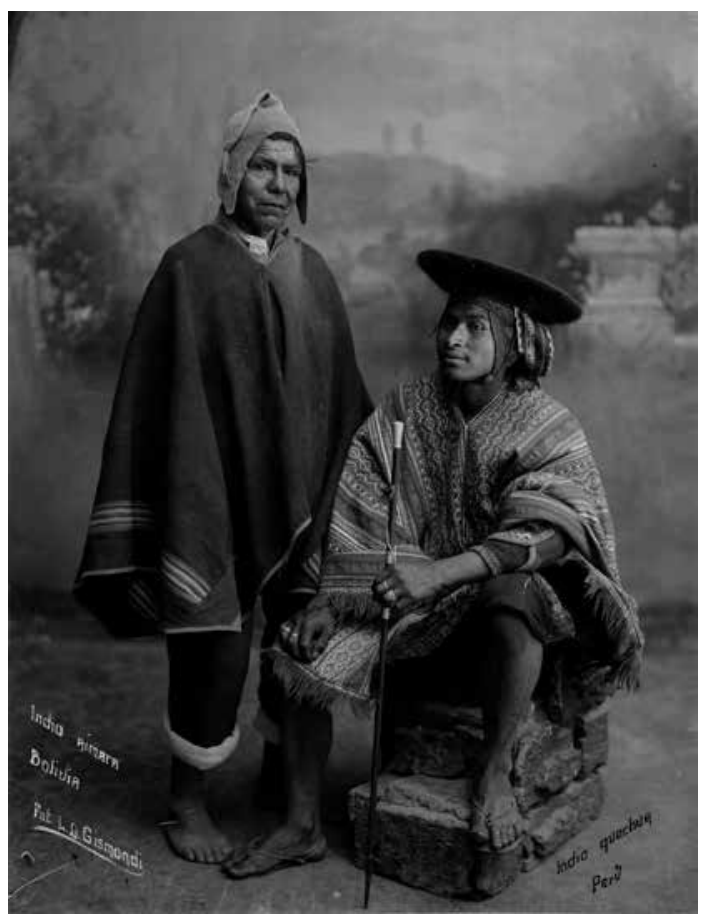

Figura 4. L.D. Gismondi. Indio aimara. Bolivia. Indio quechua. Perú. Hacia 1917. Archivo Estudio Gismondi. La Paz. Bolivia. actitudes teatrales. Sus atuendos son correctos y reales. Probablemente la gente que veía las imágenes no cuestionaba el anacronismo porque el formato y la manera de representar correspondían a lo que por entonces se esperaba que fueran las fotografías testimoniales, como Indio aimara-Bolivia, Indio Quechua-Perú, (Figura 4) la Princesa Incaica, e: Indio y Niña con Atuendos de Cusco. (Figura 5)

Este mismo tipo de manipulación y montaje del discurso visual se encuentra en la obra de otros fotógrafos contemporáneos, notablemente Max. T. Vargas, que también tuvo estudio en La Paz, desde 1905 hasta cerca de 1930.

Entre los retratos montados en estudio es particularmente notable el de los Tres Obreros Trabajando, que en realidad posan estirando una cuerda, a la manera de los Obreros de Rodín. (Figura 6) Aquí Gismondi proponía un enunciado indigenista, que tiene relación con la idea de raza superior, manifiesta en la obra contemporánea de la fotógrafa alemana Leni Rifenstahl. Por ese mismo periodo y con el concepto áulico de la fuerte raza indígena José María Velasco Maidana realizó la película Wara-Wara, 1928, y el ballet Amerindia, 


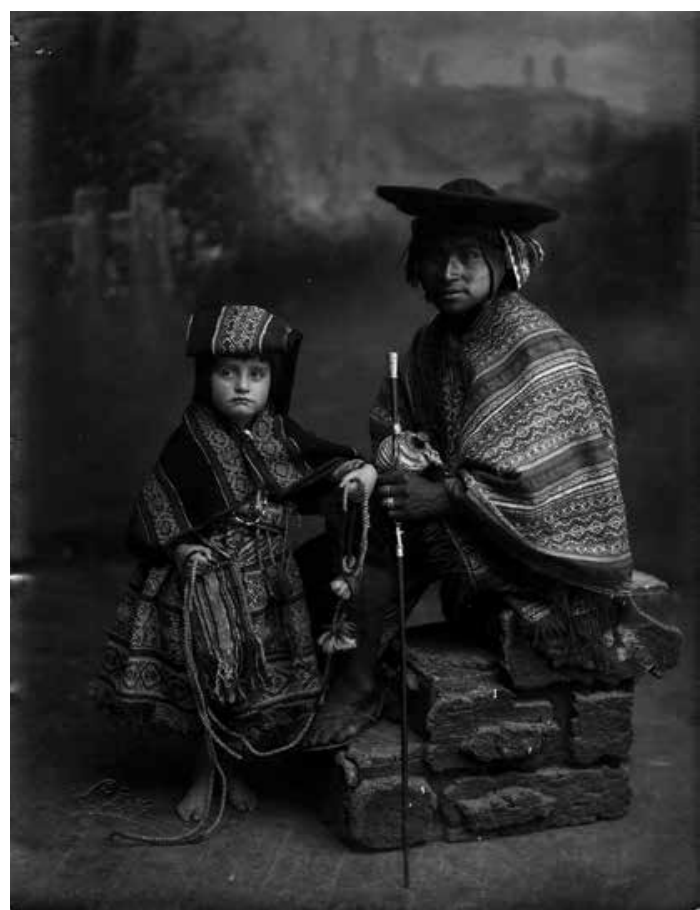

Figura 5. L.D. Gismondi. Indio y niña con atuendos de étnicos de Cusco (el indio es el mismo de la foto 4 . El que hace de niña es Luis Antonio Gismondi Morán, hijo del fotógrafo). Hacia 1917. Gelatina-plata y papel, 24 x $18 \mathrm{~cm}$. Positivo original. Colección Diran Sirinian, Buenos Aires. Argentina.
1939. Hay que tener en cuenta también la influencia que empezó a ejercer el cine, tanto en la manera de mirar como de representar.

Esto se explica, en mi opinión, tanto por el proceso ideológico e intelectual que se fue dando tanto en Bolivia como en otros países de América, de reconocimiento y redescubrimiento de sí mismos en sus realidades social y culturalmente diversas, en las que algunos sectores sociales e intelectuales se impusieron como tarea la revalorización de los habitantes originarios con el movimiento indigenista y la ideología indígena del indianismo.

Gismondi tenía una mirada inquieta y descubridora con la que transitó constantemente por las fronteras naturales -geográficas- y las simbólicas -mentales-, que caracterizan y definen a los países y sus regiones. También transitó sin solución de continuidad por los límites y fronteras culturales, raciales, sociales y económicas de la pirámide social; retrató a las elites pudientes, pero también legitimó a los componentes de las clases emergentes y dio voz e imagen a los indígenas originarios de varias partes del país y la región, e individualizó y valoró a los sectores sociales marginados, que las elites económicas y sociales ignoraban y excluían.

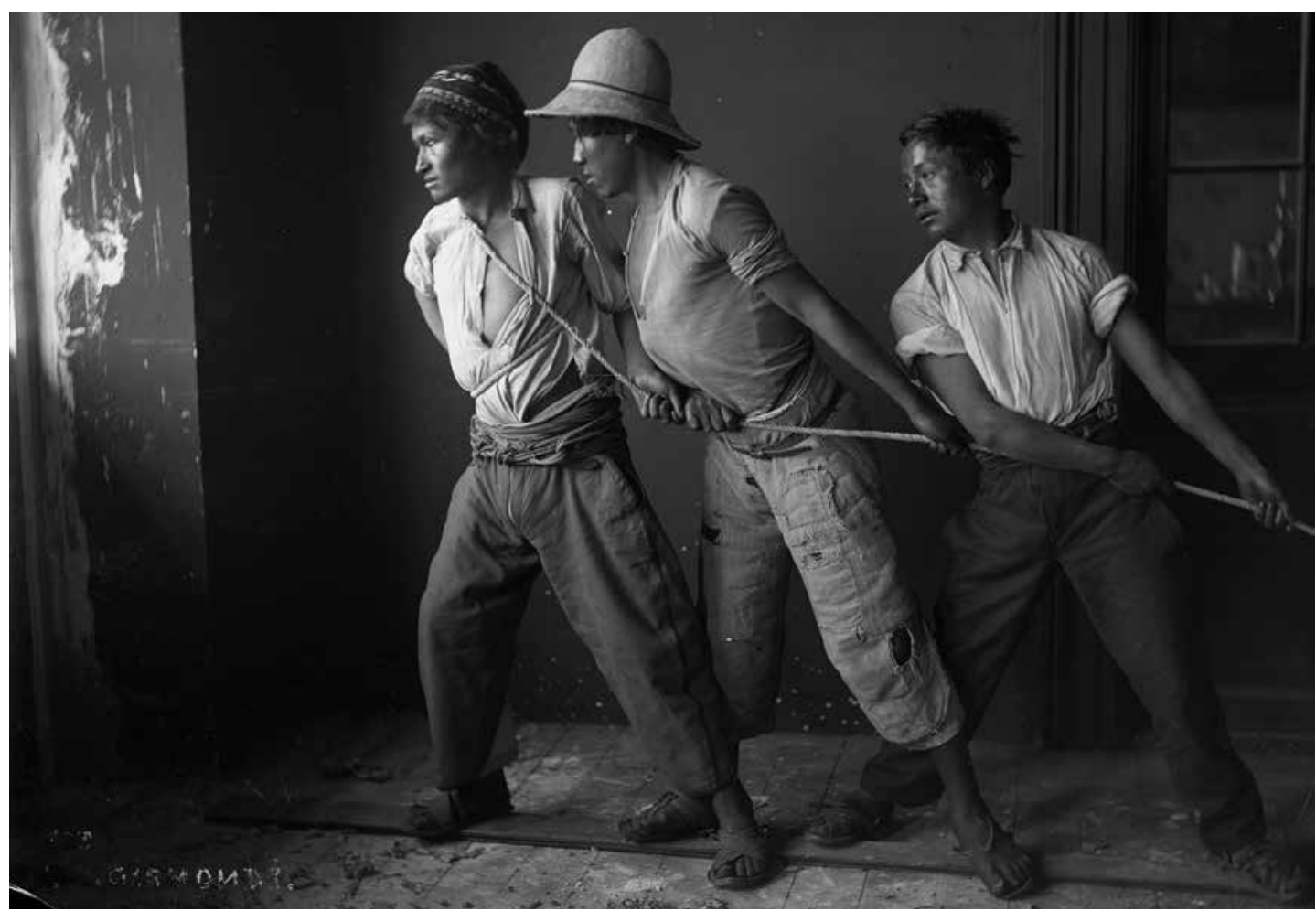

Figura 6. L.D. Gismondi. Hombres tirando una cuerda. Hacia 1925. Archivo Estudio Gismondi. La Paz. Bolivia. 


\section{Conclusión}

Gismondi vivió y trabajó en un periodo de importantes cambios sociales, políticos, culturales y estéticos. Su producción fotográfica cubrió muchos escenarios y podría clasificarse de muchas maneras. $\mathrm{Su}$ registro del territorio es una continuación del trabajo de los fotógrafos viajeros e itinerantes del siglo XIX. También se puede hacer una lectura antropológica tanto de los temas como de la manera en que él representó esos temas, ya sea en los retratos individuales o de grupo realizados en estudio o en las fotografías de personas y grupos sociales realizadas durante sus viajes. En apariencia, viendo su obra cien años después, lo menos importante de su obra son los retratos de estudio porque son convencionales, pero al mismo tiempo los retratos que realizó por interés propio son formidables y lo equiparan a los más grandes retratistas de América, al margen de la importancia relativa de los personajes retratados. Por eso se considera que Luigi Doménico Gismondi "fue el más importante de los fotógrafos bolivianos por su tarea de documentar el territorio y difundir sus imágenes" (Gutiérrez 2001).

La contribución de Luigi Doménico Gismondi a la construcción de un imaginario de país, de territorios diversos y sociedades complejas, por medio de los positivos originales, las ilustraciones en libros, revistas y periódicos, pero especialmente mediante la publicación de postales, fue importantísima y es hoy fundamental para Bolivia.

Por lo expuesto queda claro que Luigi Doménico Gismondi fue un gran fotógrafo, fiel a su tiempo, testigo de su época y consciente del valor del registro que hacía de la ciudad y del país que adoptó como suyos, por los que transitó más allá de sus fronteras naturales y simbólicas. Gismondi retrató un país, su ambiente natural y el paisaje cultural, registró sus ciudades y sus monumentos; sobre todo a los individuos y grupos de su sociedad diversa y multiétnica. Los registró para su tiempo y la posteridad, nuestro presente.

\section{Referencias Citadas}

Alarcón, R.

1925 Bolivia en el primer centenario de su independencia. The University Society. 44 East $23^{\text {nd }}$ Street New York, N.Y. U.S.A. (EE.UU.)

Buck, D.

1999 Pioneer Photography in Bolivia: Directory of Daguerreotypists \& Photographers, 1840s-1930s. Washington, D.C., U.S.A.

Estudio Gismondi

2007 Estudio Gismondi. Cien años, cuatro Generaciones. Museo Nacional de Arte. La Paz, Bolivia

Garay, A.

2011 El pueblo nuevo de Colán. El Dominical. Lima, Perú. 29 de mayo, p. 14.

Gutiérrez, R.

1997 Historia de la fotografía en Iberoamérica. Siglos XIX y XX. En: Pintura, escultura y fotografía en Iberoamérica, siglos XIX y XX. Manuales de Arte Cátedra. Madrid. España, pp. 369-370.

Martínez, B.

2006 Olivares Valdivia, retratista del Norte Chico. Acercamiento a su oficio y su mirada. En: Martínez, B. y Salgado, M. Olivares Valdivia. Fotografía y sociedad en Copiapó. 19091948. Pehuén Editores. Patrimonio Fotográfico. Santiago de Chile, p. 18

Mendoza, G

1991 Álbum de paisajes, tipos humanos y costumbres de Bolivia (1841-1869) Por Melchor María Mercado. Introducción y estudio. Banco Central de Bolivia, Archivo y Biblioteca Nacionales de Bolivia. La Paz.

Querejazu, P.

2009 Luigi Doménico Gismondi. Un fotógrafo italiano en La Paz. FAUTAPO. La Paz.

Querejazu, P.

2015 El Fotógrafo Max. T. Vargas. Su Actividad en Bolivia y sus Contemporáneos. En: Garay, A (Compil). Fotografía Max T. Vargas, Arequipa y La Paz. Universidad de Piura. Piura, Perú, pp. 79-126.

Querejazu, P.

2015 La representación de los habitantes del Chaco desde la imagen. La pintura y la fotografía como registro social de los ignorados. Simposio Internacional Chaco Ra' anga "Imaginar la Figura del Chaco". Centro de Formación de la AECID. Santa Cruz de la Sierra, Bolivia. 4, 5 y 6 de noviembre.

Querejazu, P.

2016 Imágenes y textos, los libros ilustrados con fotografías. Bolivia, lenguajes gráficos. Fundación Simón I. Patiño. La Paz.

Querejazu, P.

2016 Roberto Gerstmann, la fotografía industrial y los fotógrafos en Bolivia (1925-1940). En: Hombres y Máquinas. La minería boliviana a través del lente de Roberto Gerstmann, 1925-1936. Plural-IFEA. La Paz.

Romero, $\mathrm{S}$.

2015 Las Claudinas. Libros y sensibilidades a principios del siglo XX en Bolivia. Plural. La Paz. 